CUADERNOS DE ESTUDIOS GALLEGOS, LXIII Núm. 129 (enero-diciembre 2016), págs. 65-90

ISSN: 0210-847X

DOI: $10.3989 /$ ceg.2016.129.02

\title{
LA RELIGIÓN EN LA CULTURA CASTREÑA: ESTADO DE LA CUESTIÓN
}

\author{
MAR LlinAREs García \\ Universidad de Santiago de Compostela
}

Copyright: (C) 2016 CSIC. Este es un artículo de acceso abierto distribuido bajo los términos de una licencia de uso y distribución Creative Commons Attribution (CC-by) España 3.0.

Cómo citar/Citation: Mar LlinARES García, "La religión en la cultura castreña: estado de la cuestión”, Cuadernos de Estudios Gallegos, 63, núm. 129 (2016), págs. 65-90, DOI: http:// dx.doi.org/10.3989/ceg.2016.129.02 


\title{
LA RELIGIÓN EN LA CULTURA CASTREÑA: ESTADO DE LA CUESTIÓN
}

\begin{abstract}
RESUMEN
La cultura castreña es una cultura del área noroeste de la península Ibérica que se desarrolla en la Edad del Hierro y se mantiene parcialmente en época romana. La religión de esta cultura ha sido estudiada a través de los datos arqueológicos y epigráficos y mediante los textos clásicos de los historiadores griegos y romanos. No hay textos ni inscripciones en las lenguas propias de estas culturas, ni tampoco tradiciones míticas iconográficas en la cerámica y la escultura de estos pueblos, y consecuentemente las reconstrucciones históricas de los ritos y los mitos de sus religiones solo pueden ser fragmentarias y han estado muy condicionadas por los presupuestos metodológicos de los historiadores y los arqueólogos. El artículo ofrece una síntesis de todos estos estudios que pueden servir como guía para investigaciones futuras.

PALABRAS ClaVE: Cultura castreña, religiones, mito y ritual, datos arqueológicos, epigrafía.
\end{abstract}

\section{A RELIXIÓN NA CULTURA CASTREXA: ESTADO DA CUESTIÓN}

\section{RESUMO}

A cultura castrexa é unha cultura da área noroeste da península Ibérica que se desenvolve na Idade do Ferro e se mantén parcialmente en época romana. A relixión desta cultura ten sido estudada a partir dos datos arqueolóxicos e epigráficos, e mediante os textos clásicos dos historiadores gregos e romanos. Non hai textos nin inscripcións na lingua ou linguas propias desta cultura, nin tampouco tradicións miticas iconográficas na cerámica e a escultura destes pobos, así que as reconstruccións históricas dos ritos e mitos da sua relixión só poden ser fragmentarias e estiveron moi condicionadas polos presupostos metodolóxicos de historiadpres e arqueólogos. Este artigo ofrece unha síntese que pode servir como guía para futuras investigacións.

PALABRAS ClAVE: Cultura castrexa, relixións, mito e ritual, datos arqueolóxicos, epigrafía.

\section{RELIGION IN THE «CASTRO» CULTURE: AN OVERVIEW}

\section{AbSTRACT}

The Castro Culture is a culture of Northwestern area of the Iberian Peninsula that develops in the Iron Age and is partially maintained in Roman times. The religion of this culture has been studied through the archaeological and epigraphical data and the classical texts of Greek and roman historians. There are not texts and inscriptions in the languages of this culture and there are not mythical iconographical traditions in ceramics and sculpture of these peoples, therefore the historical reconstructions of rites and myths of these religions can be only partial and have been biased by the historical and methodological presuppositions of historians and archaeologists. This paper offers a systematic survey of these studies that can be a guide for the following researchers.

KEY WORDS: Culture of Castros or the Castro Culture, religions, myth and ritual, archaeological data, epigraphy. 
Recibido/Received: 17/11/2015

Aceptado/Accepted: 18/05/2016

U

na religión puede ser estudiada históricamente desde diferentes perspectivas, según sea considerada propia de un pueblo, de una cultura, de un grupo lingüístico o de alguna entidad de tipo político. En el ámbito de la protohistoria y la historia antigua no existieron religiones universalistas, es decir, religiones dotadas de una dinámica propia que les permite expandirse de una región a otra, o de una cultura hacia otra diferente, gracias al desarrollo del proselitismo. Por esa razón en la historia de la Galicia pre y protohistórica habrá que esperar a la difusión de las religiones orientales y a la tardía expansión del cristianismo para que se pueda hablar de fenómenos religiosos de esta naturaleza, siendo por lo tanto todas las religiones anteriores conocidas correspondientes al llamado tipo étnico, o lo que es lo mismo, religiones asociadas a ámbitos culturales, lingüísticos o políticos muy específicos.

$\mathrm{Al}$ centrarnos en el estudio de los fenómenos religiosos correspondientes a la llamada cultura castreña debemos comenzar por plantearnos una pregunta: ¿se podría hablar de una religión igualmente llamada castreña? En principio, si nos estuviésemos refiriendo a un área cultural específica, sin duda sí. El problema sin embargo es que esa área cultural ha sido definida arqueológicamente por un tipo de asentamiento, el castro, y así abarcaría un larguísimo período cronológico de más de mil años, por lo que pasar de una forma de hábitat al resto de los complejos aspectos que constituyen una sociedad o una cultura y defender su vigencia inmutable desde fines de la Edad del Bronce hasta la ocupación de su territorio por Roma o incluso más allá sin duda es muy problemático'.

Naturalmente, la labor se haría más fácil si identificásemos la cultura castreña con una gran área o koiné lingüística y cultural como el mundo celta, un mundo que abarcó desde el norte de Europa hasta Irlanda, desde allí a Asia Menor y que se extiende en otra inmensa franja cronológica que abarcaría igualmente desde fines de la Edad Bronce hasta bien entrada la Edad Media. Hay que tener en cuenta además que ese mundo celta no fue un mundo uniforme, sino un conglomerado

$\overline{1}$ Puede verse un resumen de las diferentes propuestas de periodización en la más reciente obra de síntesis, José Manuel CaAmaño Gesto, A cultura castrexa. Vol. 1. Ocupación do territorio e cultura material, A Coruña, Arrecife Edicións Galegas, 2007, págs. 15-26. 
de lenguas, dialectos, instituciones, cultos, ritos y dioses muy diversos. Por esa razón enmarcar a priori algunos o todos los fenómenos religiosos del ámbito histórico-arqueológico castreño en el cliché céltico también resultaría aventurado ${ }^{2}$.

Nuestro problema se agrava aun más si tenemos en cuenta que la cultura castreña, si admitimos esta denominación, tampoco fue uniforme ni en sus áreas arqueológicas (por ejemplo en el campo de la cerámica), ni por los tipos de hábitat, puesto que hay un claro contraste entre la zona centro-norte del actual territorio gallego y la zona sur del mismo, lo que luego fue el conventus Bracarense, mucho más próximo al mundo lusitano ${ }^{3}$. Y esos mismos contrastes pueden observarse en la distribución geográfica de algunos de los teónimos conocidos, como comentaremos más adelante.

A esa diversidad pudo añadirse otra diversidad de tipo lingüístico, pues si bien no puede negarse la existencia de teónimos, antropónimos y etnónimos de tipo celtico, también es cierto que existen muchos otros que no se ajustan a esos moldes $^{4}$. La carencia de fuentes escritas prelatinas, y el hecho de que algunos autores clásicos, como Estrabón, se negasen a veces a transcribir partiendo de sus fuentes muchos nombres indígenas, por considerarlos malsonantes, siguiendo la tradición helénica del desprecio por las lenguas alógenas, no nos ayuda mucho en este sentido. Dice el propio Estrabón (III, 2, 7):
Podría hacer la lista de estos pueblos más larga; pero renuncio a una descripción aburrida, pues a nadie le agrada oir hablar de los pletauroi, bardyetai, allótriges y otros nombres menos bellos y más ignorados.

Esta imposibilidad de elaborar una geografía lingüística del mundo de la cultura castreña es un argumento a mayores para renunciar a la hipótesis céltica en sentido uniformador, así que procederemos a continuación a describir y analizar

\footnotetext{
2 El debate sobre la celticidad o no de la cultura castreña ya tiene un largo recorrido. Como ejemplo relativamente reciente, puede verse al respecto el dossier editado por Gonzalo RUIZ ZAPATERO, "Un círculo de lectores: Miradas sobre los celtas del NO. de la Península Ibérica”, Complutum, 16 (2005), págs. 151-208. Puesto que es una cuestión sobre la que no existe consenso, utilizar la hipótesis céltica para intentar justificar una supuesta unidad de la cultura castreña solo añade problemas a cuestiones como la cronología o los límites geográficos, que a su vez tampoco están solucionadas.

3 En J. M. CaAmaño Gesto, A cultura castrexa ..., págs. 28-35 puede verse una aproximación breve a los límites geográficos propuestos para la cultura castreña.

${ }_{4}$ Puede verse una revisión de las diferentes posturas sobre las lenguas prerromanas del Noroeste en Blanca María Prósper, Lengua y religiones prerromanas del occidente de la Península Ibérica, Salamanca, Ediciones Universidad de Salamanca, 2002, págs. 16 y ss., aunque desde una perspectiva exclusivamente lingüística, que excluye cualquier otro elemento a considerar.
} 
los hechos y fenómenos religiosos del mundo castreño, teniendo en cuenta la naturaleza particular y heterogénea de las fuentes que poseemos, y considerando una zona definida de forma sin duda algo ambigua que incluye el territorio de la actual Galicia, el este de Asturias hasta el río Navia, y los territorios del actual Portugal entre el Miño y el Duero.

En primer lugar, tenemos las fuentes arqueológicas correspondientes al área geográfica y al ámbito cronológico que nos corresponde estudiar, que se van a utilizar limitando la comparación con otras culturas -anteriores o posteriores- lo más posible. Estas fuentes han sido utilizadas como elemento para intentar establecer períodos culturales dentro de la zona. Sin entrar a discutir este punto ${ }^{5}$, es evidente que no es posible sostener la existencia de una única "cultura", inmutable e idéntica a sí misma durante más de 1.000 años, y lo mismo se puede decir respecto de los aspectos religiosos: los períodos iniciales apenas podremos señalar algunas cosas, y para los más tardíos, la información es mayor y de fuentes más diversas, lo que supone la paradoja de que básicamente dependemos de fuentes no estrictamente emic, por utilizar la clásica denominación de la teoría antropológica.

Si se define religión como el conjunto de discursos y acciones (o creencias y ritos en la terminología más clásica) que relacionan al mundo humano con un mundo no humano (suprahumano) previamente definido por ese discurso y situado en un espacio determinado, y se admite su posible existencia como fenómeno más o menos discreto en cualquier cultura humana y en cualquier época, y por lo tanto se la busca, el acceso a este conjunto a partir de un registro material parcial evidentemente puede ser complicado ${ }^{6}$.

Los aspectos relacionados con los actos y los gestos (ritos y cultos) por una parte y los enunciados (orales o escritos: mitos, oraciones, maldiciones, etc.) posiblemente no agoten el campo de la religión, pero al menos incluyen su dimensión social o colectiva. Es obvio que en este corto listado falta la importante

\footnotetext{
5 Véanse supra, notas 1 y 3.

6 De ahí las cautelas que se observan en la bibliografía especializada respecto de la denominación de aquellos aspectos de la vida colectiva de las sociedades humanas que no están directamente relacionados con la supervivencia, aunque aquellos autores adscritos a las corrientes que se relacionan con el neoevolucionismo o la ecología cultural asuman que esta esfera "ideológica" sí está supeditada a la esfera técnica. Estas cautelas no significan necesariamente que no se hagan afirmaciones sobre la vida religiosa, "psíquica" o "ritual" de las culturas pre y protohistóricas, aunque por lo general sin definir los parámetros que permitan diferenciar arqueológicamente qué elementos son adscribibles a esta esfera religiosa y cuáles no, o bien en qué contexto un determinado elemento material puede pasar del campo de lo cotidiano al campo de lo religioso o simbólico. En la mayoría de los casos, esta cuestión se deja a la intuición o a la extrañeza, además de por supuesto a la comparación etnográfica más o menos fina. Paradójicamente, se utiliza a veces la comparación directa con la propia experiencia del observador, y así, la identificación de posibles imágenes de culto depende en parte de su comparación con las tradiciones cristianas, que suelen formar parte del trasfondo cultural de los investigadores.
} 
dimensión de la vivencia, pero es igualmente obvio que, desde un punto de vista estrictamente arqueológico, esta dimensión no sólo es inaccesible, sino que quizás no tiene sentido planteársela. Las reconstrucciones arqueológicas a partir del registro estrictamente material pueden intentar acceder entonces, de forma siempre parcial, a los actos y gestos, a partir de los objetos, las imágenes y los escenarios presentes en ese registro, que forman parte del campo de la religión, pero evidentemente no a los enunciados ${ }^{7}$.

En segundo lugar, nos encontramos con las fuentes literarias clásicas, sometidas por supuesto a la crítica histórica y filológica ${ }^{8}$. El hecho de que sean fuentes textuales podría permitir el acceso a la esfera de los enunciados, y dentro de ellos a los relacionados con el campo de la religión, pero en nuestro caso no nos presentan mitos, oraciones, etc., es decir, aquellos aspectos relacionados directamente con esta esfera. Además, las fuentes textuales para el territorio que nos ocupa están circunscritas a una época relativamente tardía, aunque en muchos casos se refieran a situaciones prerromanas, aunque esto no supone que sea posible una trasposición directa. La fuente más importante es la obra de Estrabón (64 a.C.-19 d.C. aprox.), que era un ciudadano griego, de cuya amplísima obra titulada Comentarios históricos apenas quedan unos fragmentos. Sin embargo, se conserva completa su Geografía, redactada entre los años 29 a.C. y 7 d.C. En su libro III se encuentran los datos referidos a toda la zona norte de la península Ibérica en conjunto, con lo cual los datos referidos a pueblos situados dentro de las fronteras admitidas para la cultura castreña, como los ártabros o los galaicos, o bien a otros fuera de este ámbito, como los cántabros, o incluso aquellas referencias genéricas a los "montañeses" pueden considerarse básicamente intercambiables", lo que no siempre es una ventaja, puesto que desdibuja los aspectos más concretos relacionados con cada uno de los pueblos que menciona. Estrabón jamás se desplazó a esta región, por lo que utiliza distintos tipos de fuentes para confeccionar su obra. Consultó obras de autores anteriores, griegos como él, sobre todo Posidonio, y seguramente a través de él Artemidoro y Polibio; también utilizó noticias de funcionarios romanos, viajeros o comerciantes, datos en general anecdóticos y no técnicos ${ }^{10}$.

\footnotetext{
7 Véase sobre este problema Mar Llinares García, Los lenguajes del silencio. Arqueologías de la religión, Madrid, Akal, 2012, págs. 44-47.

8 Las fuentes pueden verse en Adolf Schulten y Pedro Bosch Gimpera (eds.), Fontes Hispaniae Antiquae, Barcelona, Bosch, 1922-1959; Ana Romero Masiá y Xosé Manuel Pose Mesura, Galicia nos textos clásicos, A Coruña, Museo Arqueolóxico Provincial, 1988; Antonio Balboa Salgado, Gallaecia nas fontes clásicas, Santiago de Compostela, Servicio de Publicacións da Universidade de Santiago de Compostela, 1996; las divisiones territoriales utilizadas por los diferentes autores para seleccionar las fuentes no siempre coinciden.

9 José Carlos Bermejo Barrera, Mitología y mitos de la Hispania prerromana II, Madrid, Akal, 1986, cap. I.

${ }^{10}$ Daniela Dueck, Strabo of Amasia. A Greek Man of Letters in Augustan Rome, Londres, Routledge, 2000.
} 
De todos modos, y a pesar de la necesidad de tener en cuenta sus características concretas, negarnos a utilizar estas fuentes sería no solo inadmisible desde el punto de vista del historiador, sino que además sería imposible, puesto que se conocen, están presentes en la historiografía desde hace mucho tiempo, y no se puede actuar como si no existiesen.

En tercer lugar, nos encontramos con las fuentes epigráficas latinas, que respecto al asunto que nos ocupa, contienen según algunos autores cerca de doscientos nombres y epítetos de dioses, interpretables en unos casos e ininteligibles en otros, pero que dan muestra inequívoca de la permanencia de los cultos indígenas en la época imperial romana. Las fuentes epigráficas comparten con las textuales el hecho de ser de cronología tardía, y además estar escritas en su inmensa mayoría en la lengua de los conquistadores, con los problemas añadidos derivados de la adaptación de la grafía del latín a las lenguas indígenas ${ }^{11}$. Presentan además algunos problemas que complican su uso ${ }^{12}$. Un primer obstáculo es la naturaleza del material sobre el que están realizadas las inscripciones. La gran mayoría están sobre granito, y este grabado está normalmente mal conservado, no sólo por el desgaste debido al tiempo y a las condiciones de conservación, sino también por la reutilización de las piedras. Las lecturas y dataciones son a veces muy difíciles. En la gran mayoría de los casos sólo se puede señalar una fecha aproximada. El grueso de las fuentes epigráficas se concentra en los siglos I y II d.C., comenzando a menguar a partir del siglo III, con lo que nos encontramos en la misma situación paradójica que señalábamos antes: las fuentes sobre las divinidades no romanas son de época ya romana.

Un segundo problema son los propios textos. Hay muy pocas inscripciones relativas a las estructuras oficiales, tanto romanas como las posibles indígenas. La gran mayoría de las inscripciones son dedicatorias funerarias modestas, lo que tiene ventajas e inconvenientes. En cuanto a las ventajas, podrían permitir una aproximación al estudio de las estructuras familiares, la sociedad y la onomástica. Pero presentan los inconvenientes de ser demasiado breves. En el caso de las inscripciones dedicadas a divinidades indígenas, por ejemplo, son el único testimonio sobre el panteón o panteones de la zona que nos ocupa, puesto que no se conserva ningún mito. Y en la gran mayoría de estos casos solo conocemos el nombre de la divinidad, lo que no nos dice demasiado de su carácter; incluso a veces ni siquiera sabemos si es masculina o femenina ${ }^{13}$.

${ }^{11}$ Éste es el caso de las inscripciones lusitanas; véase B. M. Prósper, Lengua y religiones..., págs. 37-38.

${ }^{12}$ Véase Alain Tranoy, La Galice romaine. Recherches sur le nord-ouest de la péninsula ibérique dans l'Antiquité, París, Diffusion de Boccard, 1981, págs. 16 y ss.

${ }^{13}$ Los documentos literarios y epigráficos relativos a los mitos, cultos y religiones de la península Ibérica prerromana han sido editados a lo largo de los años por José María BlázQuez MarTínez, 
Únicamente en el caso precisamente de estos epígrafes, tanto los dedicados a divinidades como los funerarios, de los que no vamos a ocuparnos aquí en cuanto tales, podríamos aproximarnos a algo parecido a un enunciado de tipo religioso dentro de los testimonios que se conservan de la religión en la cultura castreña, pero su brevedad y los muchos problemas de interpretación de los propios nombres de las divinidades impiden ir más allá. Retomaremos esta cuestión más adelante.

En cualquier caso, las fuentes utilizadas lo serán porque son consideradas como tales en el consenso de las comunidades científicas de arqueólogos e historiadores. De entre ellas se destacarán aquellos datos más seguros y se seleccionarán las interpretaciones mayoritariamente aceptadas, dejando a un lado hipótesis mal fundadas e interpretaciones aventuradas. Todo esto intentando establecer dentro de lo posible los momentos cronológicos a los que estamos refiriendo las fuentes, lo que no siempre es totalmente factible.

\section{Ritos Y CULTOS}

A pesar del encabezamiento de este apartado, habría que señalar de entrada que no queremos caer en el abuso de suponer que cualquier comportamiento ritualizado, por el simple hecho de serlo, es de carácter religioso. No obstante, la escasez de fuentes nos lleva a explorar todos aquellos indicios que nos permitan entrever el campo de la religión castreña, a pesar de ser conscientes de que se corre un cierto peligro de ofrecer una visión un tanto vaga y uniformizadora, territorial y cronológicamente. Intentaremos evitarlo en lo posible.

Los rituales principales que parece razonable proponer a partir del registro arqueológico castreño serían los sacrificios y ofrendas, los posibles ritos de iniciación, y los rituales de comensalidad, cuyas dimensiones estrictamente religiosas son quizás menos explícitas, aunque quizás puedan estar conectados, además de a dimensiones sociales de otro tipo, al sacrificio.

Las evidencias sobre sacrificios, cuyo carácter concreto será difícil de establecer, son principalmente los bronces votivos, inscripciones rupestres como la de Cabeço das Fraguas e Lamas de Moledo (con la precaución de que en este caso se trata de inscripciones lusitanas de una época ya romana), y también los textos, cuyas características generales ya hemos comentado, referentes a los sacrificios que se realizaban a Ares (Estrabón, III, 3, 7).

Religiones Primitivas de Hispania. I. Fuentes Literarias y epigráficas, Madrid, CSIC, 1962; Diccionario de las religiones Primitivas de Hispania, Madrid, Istmo, 1978; Imagen y Mito, Madrid, Ediciones Cristiandad, 1980; Primitivas Religiones Ibéricas. II. Religiones Prerromanas, Madrid, Ediciones Cristiandad, 1983; Religiones de la Hispania Antigua, Madrid, Cátedra, 1991. 
Con la denominación general de "bronces votivos" se conocen varios ejemplares de distinto carácter, la mayoría aparecidos fuera de contexto y de procedencia diversa, dudosa en algunos casos y desconocida en otros: son los bronces de Castelo de Moreira (Celorico de Basto, Portugal); el carro de Vilela (Portugal); los que se conservan en el Instituto de Valencia de Don Juan, y en el Museo Arqueológico Nacional (dos ejemplares), los tres de procedencia desconocida; el de Lalín; el de Cariño y el de Punta Atalaia (Cervo, Lugo) ${ }^{14}$.

En estas piezas aparecen representados personajes humanos, calderos, torques y animales ${ }^{15}$, precisamente los animales que se mencionan en las inscripciones rupestres de Cabeço das Fraguas y Lamas de Moledo, que no obstante hay que recordar que están fuera de los límites de la zona habitualmente considerada castreña (aunque en el campo de la religión estas fronteras parecen bastante difusas) y son de época muy posterior, con lo que hay que tener la precaución de evitar dar la impresión de una continuidad prerromana utópica y ucrónica.

Como se ha señalado, en la mayoría de los casos no existe contexto para el hallazgo de estas piezas o ni siquiera está clara su procedencia, aunque hay un acuerdo general en asignar todos estos bronces a la cultura castreña del noroeste. No obstante, respecto de la cronología y del área de producción y uso, sí se pueden hacer algunas aproximaciones ${ }^{16}$.

En el área bracarense es donde se recogen las piezas más complejas, y donde se registra una trayectoria más larga, empezando por los carros votivos del Bronce Final. Los carros con una escena de procesión pertenecerían a la Edad del Hierro, entre los siglos IV-III a.C. Respecto de las hachitas, su hallazgo en castros de cronología avanzada (mediados del siglo II a.C. - siglo I d.C.) las llevarían a un momento final de las cultura castreña. Para Rey Castiñeira, el bronce de Castelo da Moreira corresponde estilísticamente a un momento intermedio entre los carros y las pequeñas hachas ${ }^{17}$.

Respecto del castreño septentrional, el ejemplar de Cariño estaría próximo al de Castelo de Moreira, mientras que el recientemente aparecido de Punta Atalaia

\footnotetext{
${ }^{14}$ Véanse las descripciones en Armando Coelho DA SiLVA, A cultura castreja no Noroeste de Portugal, Câmara Municipal de Paços de Ferreira-Museu Arqueológico da Citânia de Sanfins, 1986, p. 183 para el carro de Vilela; Xosé Lois Armada Pita y Óscar García Vuelta, "Bronces con motivos de sacrificio del área noroccidental de la península Ibérica", Archivo Español de Arqueología, 76 (2003), págs 47-75; Eva CASTRO VIGO, "Un nuevo ejemplo de los llamados bronces votivos sacrificiales”, Gallaecia, 28 (2009), págs. 131-138 para el bronce de Punta Atalaia; Javier Rodríguez Corral, A Galicia castrexa, Santiago, Lóstrego, 2009, págs. 166-167.

${ }^{15}$ Véase una buena descripción en Josefa ReY CastiÑEIRA, "A metalurxia castrexa" en J.M. Hidalgo Cuñarro (coord.), Arte e cultura de Galicia e norte de Portugal. Arqueoloxía, vol. 2, Vigo, Nova Galicia Edicións, 2005, págs. 57-83, esp. págs. 70-74.

${ }^{16}$ Seguimos en este punto a J. Rey CAstiÑeIRA, “A metalurxia...”, págs. 74 ss.

17 J. Rey Castiñeira, “A metalurxia...”, p. 74.
} 
se localizó en un derrumbe de un muro de este castro, en un contexto datado entre el siglo I a.C. y el II d.C. ${ }^{18}$.

El carácter concreto del sacrificio se nos escapa. Es muy difícil dejar de mencionar las inscripciones rupestres de Cabeço das Fraguas y Lamas de Moledo, donde la ofrenda de animales para el sacrificio está clara, aunque el nombre y el carácter de las divinidades a las que se hace, no tanto ${ }^{19}$; además, como ya hemos señalado, su cronología es muy posterior y se localizan en el margen exterior de la zona habitualmente considerada castreña, y aunque sea tentador trazar una línea de continuidad entre los carros con calderos del Bronce Final, los bronces castreños y las inscripciones en esta área limítrofe, no es posible sostener que no haya habido ningún cambio en la naturaleza de los sacrificios a lo largo de ocho siglos, aunque el acto ritual en sí se haya mantenido.

También es casi imposible no acudir a los textos de Estrabón donde se mencionan los sacrificios adivinatorios de los lusitanos (III, 3, 6):

Los lusitanos hacen sacrificios y examinan las vísceras sin separarlas del cuerpo; observan asimismo las venas del pecho y adivinan palpando. También auscultan las vísceras de los prisioneros, cubriéndolas con ságoi. Cuando la víctima cae por mano del hieróskopos, hacen una primera predicción por la caída del cadáver. Amputan las manos derechas de los cautivos y las consagran a los dioses,

y también los sacrificios que realizan los “montañeses” (III, 3, 7):

los montañeses sacrifican machos cabríos a Ares y también cautivos y caballos; suelen hacer hecatombes de cada especie de víctima al uso griego y por decirlo al modo de Píndaro "inmolan todo un centenar",

aunque si bien los machos cabríos parecen estar representados en estas piezas, los caballos no lo están ${ }^{20}$. En cuanto al sacrificio de cautivos de guerra, además

\footnotetext{
18 E. Castro Vigo, "Un nuevo ejemplo...".

19 Véanse las distintas lecturas y traducciones propuestas en B.M. PrósPer, Lengua y religiones..., caps. II y III.

${ }^{20}$ Sobre el análisis del vocabulario del sacrificio que utiliza Estrabón, véase José Carlos BERMEJO Barrera, Sociedade e relixión na Galicia antiga, Santiago de Compostela, Lóstrego, 2008, págs. 115 y ss.
} 
de suponer una nueva marca de barbarie dentro del discurso de los conquistadores romanos, se ha querido ver su reflejo en la presencia de las famosas cabezas cortadas, cuya aparición ha sido interpretada como una señal de la exacerbación del conflicto con Roma ${ }^{21}$.

En estos bronces, además de animales, aparecen otros elementos que nos permiten relacionar el sacrificio con otros rituales posibles. Así, los torques (que aparecen en todos los ejemplares mencionados menos uno) y la presencia de personajes humanos, posiblemente hombres, con armas y/o torques o escudos nos llevarían al mundo de la guerra, y quizás a los posibles ritos de iniciación de los guerreros; de la misma forma, la presencia de calderos en los bronces y en el registro nos permiten establecer una posible relación con los ritos de comensa$\operatorname{lidad}^{22}$ (véase Tabla 1).

Tabla 1. Torques, calderos y personajes armados en los bronces votivos del Noroeste.

(Fuente: elaboración propia a partir de la bibliografía citada en n. 14).

\begin{tabular}{|c|c|c|c|c|c|c|c|}
\hline & Torques & Caldero & Escudo & $\begin{array}{c}\text { Pers. con } \\
\text { espada/puñal }\end{array}$ & $\begin{array}{l}\text { Pers. con } \\
\text { torques }\end{array}$ & $\begin{array}{c}\text { Pers. con } \\
\text { espada/puñal }\end{array}$ & $\begin{array}{c}\text { Pers. con } \\
\text { espada/puñal } \\
\text { y escudo }\end{array}$ \\
\hline Cariño & $x$ & & $x ?$ & & & & \\
\hline C. de Moreira & $x$ & $x$ & & $x$ & & & \\
\hline IVDJ & $x$ & $x$ & & $x$ & $x$ & $x$ & \\
\hline Lalín & $x$ & $x$ & & & & & \\
\hline MAN I & & $x$ & & & & & \\
\hline MAN II & $x$ & $x$ & & & & & \\
\hline Punta Atalaia & $x$ & $x ?$ & & & & & \\
\hline Vilela & $x$ & $x$ & & & & & $x x x x$ \\
\hline
\end{tabular}

Respecto del mundo de la guerra, sus aspectos más estrictamente religiosos o rituales se centrarían en los cultos a las divinidades relacionadas con ese ámbito (lo veremos más adelante cuando hablemos del panteón castreño) y en los posibles ritos de iniciación por los que pasarían los jóvenes, o algunos de ellos al menos,

\footnotetext{
${ }^{21}$ Alfredo González Ruibal, "Galaicos. Poder y comunidad en el Noroeste de la Península Ibérica (1200 a.C.-50 d.C.)”, Brigantium, vol. 18-19 (2006-2007), págs. 444 y ss.; sobre la amputación de las manos diestras, véase J. Rodríguez Corral, A Galicia castrexa ..., págs. 208 y ss.

${ }^{22}$ Véase infra sobre los calderos y la comensalidad.
} 
si se acepta la existencia de elites o "aristocracias" guerreras ${ }^{23}$, para alcanzar precisamente el estatuto de guerreros ${ }^{24}$.

La aparición de torques representados en los bronces votivos podría indicar la relación de los sacrificios con el mundo guerrero de los hombres, aunque en el carro de Vilela aparecen figuras que pueden ser femeninas, lo que podría llevar a pensar en una dimensión más comunitaria, que de todos modos no es incompatible con lo anterior ${ }^{25}$. El torques va unido a la figura del guerrero, como se puede ver en las estatuas de los llamados guerreros galaico-lusitanos o castreños, cuya cronología sin embargo no está totalmente establecida ${ }^{26}$, y también aparecen en depósitos en zonas fuera de los castros $^{27}$. Precisamente estos depósitos de torques fuera de los castros han sido puestos en relación con el mundo ritual masculino, al que también se asocian las famosas saunas.

El descubrimiento de unas edificaciones singulares en los castros meridionales dio lugar a un gran debate sobre su funcionalidad ${ }^{28}$, aunque en la actualidad su uso termal está claramente establecido. Lo que no todo el mundo comparte es la dimensión concreta de ese uso termal: algunos autores lo consideran meramente balneario, mientras que otros defienden un uso ritual, cuyo carácter de todos modos no está totalmente claro. En cuanto a su cronología, parece haber un cierto

\footnotetext{
${ }^{23}$ Véase A. González Ruibal, “Galaicos...”, pág. 401.

${ }^{24}$ No vamos a entrar en la discusión sobre la naturaleza belicosa o pacífica de las comunidades prerromanas del norte de Hispania, puesto que todas las evidencias conducen a la misma dirección: la dimensión guerrera es palmaria; véase no obstante un resumen de los argumentos en J. RoDRíGUEZ CORRAL, A Galicia castrexa..., págs. 201 y ss. Sobre el caso específico del castreño en la zona noroeste de Portugal, véase Francisco Manuel Veleda Reimâo Quiroga, War and Castros. New approaches to the northwestern Portuguese Iron Age, Oxford, Archaeopress, 2003 (BAR International Series $1198)$.

${ }^{25}$ Véase la interpretación de Andrés Pena Graña, "Cerimonias celtas de entronización real na Galicia”, Anuario Brigantino, 27 (2004), págs. 117-160, de este bronce como la alusión a un ritual fundacional tras una ceremonia de entronización o investidura.

${ }^{26}$ Véase A. C. DA SiLva, A cultura castreja..., p. 292, que los sitúa en el siglo I d.C, aunque dentro de la tradición indígena; A. GonZÁlez Ruibal, "Galaicos...", p. 389, sin embargo, los adjudica a los siglos II-I a.C. Véase un análisis de las armas representadas en las estatuas de guerreros en Fernando QuesADA SANZ, “¿Espejos de piedra? Las imágenes de armas en las estatuas de los guerreros llamados galaicos", Madrider Mitteilungen, 44 (2003), págs. 87-112, donde concluye que no es posible precisar una cronología más allá de una horquilla que va desde mediados del siglo II a.C a mediados del siglo I d.C.

${ }^{27}$ Véase A. González Ruibal, "Galaicos...”, pág. 420 y pág. 588; J. Rodríguez Corral, A Galicia castrexa ..., pág. 183.

${ }^{28}$ Véase el resumen de las posturas en A. González Ruibal, "Galaicos...”, pág. 570; Ángel VitLA VALDÉs, "Santuarios "urbanos" en la protohistoria cantábrica: algunas consideraciones sobre el significado y función de las saunas castreñas", Boletín del Real Instituo de Estudios Asturianos, LXV, 177 (enero-junio.2011), págs. 9-46; Marco V. García Quintela y Manuel Santos-EstéveZ, "Iron Age saunas of Northern Portugal: state of the art and research perspectives", Oxford Journal Of Archaeology, 34 (1) (2015), págs. 67-95, esp. págs. 73-79.
} 
acuerdo en colocar su origen hacia comienzos de la Segunda Edad del Hierro. Los motivos que decoran las grandes losas que cierran las saunas meridionales, conocidas como pedras formosas, son los mismos que aparecen representados en la cerámica de los siglos III-II a.C. ${ }^{29}$, aunque como tales motivos tuvieron una vida muy $\operatorname{larga} a^{30}$.

Respecto del uso ritual concreto al que se dedicarían estas construcciones, la hipótesis más aceptada en la actualidad es la que las asocia con los ritos de iniciación de nuevos guerreros, aportando como apoyo, además de la propia estructura de las saunas, el texto de Estrabón (III, 3, 6) en el que se dice que los pueblos que habitaban sobre el río Duero viven como los espartanos, bañándose con el sudor obtenido con piedras candentes. Las saunas meridionales estarían situadas en posiciones más excéntricas, cerca de las puertas del castro (lo que también las pondría en relación con las zonas liminales en las que aparecen depósitos de torques, por ejemplo), mientras que las saunas septentrionales están en general intramuros, aunque también con una posición de cierto dominio sobre los accesos ${ }^{31}$.

El hecho de la posible existencia de ritos de paso hacia la edad adulta asociados a la actividad bélica en general se suele asociar también al texto de Estrabón donde se describe la vida de asaltos y bandidaje de los pueblos situados entre el Tajo y los ártabros (Estrabón, III, 3, 5) y especialmente el pasaje de Diodoro $(5,34,4)$, referido en este caso a los lusitanos, donde describe cómo grupos de jóvenes de la misma edad forman grupos provistos de armamento ligero que se dedican a saquear Iberia. Si bien es necesario tener en cuenta siempre la naturaleza de estas fuentes y su cronología, estas descripciones son compatibles con la existencia de un sistema de grupos de edad en el que bandas de jóvenes se ejercitan en la actividad guerrera marginal hasta que consiguen el estatuto de adulto. La interpretación del relieve de Formigueiros (donde se representa una fila de caballos, uno de ellos montado) como un posible ejemplo de hazaña cinegética o militar, en la que el robo o la captura del ganado estarían asociados a la exhibición de las capacidades bélica de los hombres, es coherente con esta visión ${ }^{32}$.

Respecto de los rituales de comensalidad, que es el otro aspecto que se puede relacionar con el ritual del sacrificio, los animales muertos en el sacrificio

\footnotetext{
${ }_{29}$ Josefa ReY CAStiÑEIRA, "Referencias de tempo na cultura material dos castros galegos", en J. M. Hidalgo Cuñarro (coord.), A cultura castrexa a debate (Actas do Curso de Verán da Universidade de Vigo, Tui, 17-19 de xullo de 1995), Tui, Instituto de Estudios Tudenses, 1996, págs. 157-206.

${ }^{30}$ Véase J. Rodríguez Corral, A Galicia castrexa ..., págs. 190 y ss.; véase también en págs. 189 y ss. una descripción de los dos tipos principales establecidos.

${ }^{31}$ Véase una discusión sobre las diferencias constructivas y quizás funcionales entre las saunas del sur y las del norte en A. GonzÁlez Ruibal, "Galaicos...”, págs. 572 y ss., M.V. García Quintela y M. SAntos-Estévez, "Iron Age saunas...”, págs. 67-73.

${ }^{32}$ Mar Llinares García, "El jinete y sus caballos: a propósito del relieve castreño de Formigueiro (Amoeiro, Ourense)", Madrider Mitteilungen, 49 (2008), págs. 229-237.
} 
sangriento en general se destinaban en las culturas antiguas al consumo colectivo. En el caso del noroeste de Hispania no hay menciones a tal consumo, pero sí existen evidencias, tanto en el registro como en los textos más tardíos, de la importancia de la comensalidad. El punto de partida es por un lado la aparición de elementos relacionados con el consumo de carne en el registro arqueológico (ganchos de carnes, asadores), algunos restos de consumo que podrían estar asociados a estructuras que podemos llamar comunitarias ${ }^{33}$, la presencia de calderos a lo largo de todas las fases de la cultura castreña, y por supuesto, una vez más, un texto de Estrabón (III, 3, 7):

\begin{abstract}
Comen sentados sobre bancos construidos alrededor de las paredes, alineándose en ellos según sus edades y dignidades; los alimentos se hacen circular de mano en mano; mientras beben, danzan los hombres al son de flautas y trompetas, saltando en alto y cayendo en genuflexión.
\end{abstract}

La presencia de bancos adosados a las paredes de las construcciones castreñas es habitual, tanto en casas de pequeño tamaño como en cabañas de grandes dimensiones, como el caso de Briteiros ${ }^{34}$. La mención de edades y dignidades, además de la dimensión social o política, también podría relacionarse con el aspecto anterior de la existencia de grupos de edad.

Es destacable la importancia del caldero a lo largo del desarrollo de la cultura castreña, lo que por supuesto no supone afirmar que su uso y su significación se hayan mantenido sin cambios a lo largo del tiempo ${ }^{35}$. A diferencia de lo que sucedía en el Bronce Final, donde los calderos se encuentran en depósitos considerados generalmente votivos (Hío, Baiôes), en la edad del Hierro en general aparecen dentro de los castros $^{36}$. Destacan en este aspecto las sítulas metálicas castreñas: calderos de bronce fundido, con decoración geométrica en línea con las decoraciones de otros elementos de la cultura castreña, realizados en molde ${ }^{37}$.

\footnotetext{
${ }^{33}$ En concreto en un relleno en la sauna de Punta dos Padros, Ortigueira; véase Rafael Penedo RoMERO, "Informe sobre los restos óseos del yacimiento castreño de Punta dos Prados (Ortigueira, A Coruña): campañas de 1987 y 1988”, Brigantium, 9 (1995-1996), págs. 61-74; también en el recinto central de Monte Mozinho, como señalaremos en el epígrafe siguiente.

${ }^{34}$ A.C. DA Silva, A cultura castreja ..., pág. 53.

${ }^{35}$ Véanse los datos sobre los hallazgos en A. GonzÁlez Ruibal, "Galaicos...", págs. 212 y ss. y págs. 593 y ss.

${ }^{36}$ Véase la enumeración de los hallazgos principales en A. GonZÁlez Ruibal, "Galaicos...", pág. 214 y pág. 594.

${ }^{37}$ Véase J. Rey CASTIÑEIRA, “A metalurxia...”, págs. 74 y ss., a cuya descripción y análisis técnico nos remitimos.
} 
Esta aparición dentro de los recintos castreños se relacionaría con un uso tanto doméstico, lo que no quiere decir necesariamente cotidiano, si lo relacionamos con los banquetes mencionados en las fuentes, como con los sacrificios, puesto que, como se ha visto en la Tabla 1, aparece en prácticamente la totalidad de los bronces votivos antes mencionados. En contra de su uso estrictamente cotidiano, no obstante, milita el hecho de que los hallazgos son excepcionales, si bien su extensión geográfica es muy amplia, tanto en la zona septentrional como en el sur, en pequeños castros, en los oppida o incluso en las ciudades de fundación romana. También indican esta importancia simbólica el hecho de que su diseño responda a un canon establecido y su fabricación sea cuidadosa, así como el hecho de que existan imitaciones en cerámica que responden también a un modelo generalizado que se mantiene bastante al margen de las tradiciones alfareras de cada zona ${ }^{38}$.

Es curioso señalar que, a pesar de la sorpresa de Estrabón por la existencia de bancos circulares para la celebración del banquete sentado, en Grecia en determinados santuarios como el Kabirion de Tebas existían bancos circulares para la celebración de los banquetes que seguían a los sacrificios ${ }^{39}$. Si bien no nos hemos decantado por utilizar la comparación etnográfica, lo vamos a hacer en este caso, puesto que sería la primera vez que se mencionan estos paralelos.

Los tracios también celebraban el banquete sentados en círculo, como los celtas, según Jenofonte (Anábasis, 7, 3, 21) y Ateneo (Deipnosophistai, 4, 151B-152 B). Lo mismo harían los ilirios y los egipcios según Teopompo (F.Gr.Hist. 115, F.39= Ateneo, 10.443 A), y Ateneo ( 5, 191 F). En Macedonia solo los hombres podían participar en el banquete tumbados, mientras que los jóvenes quedarían de pie o sentados, según Aristóteles (Politeia, VII, 15, 9). El paso de esas posturas a la reclinada estaría marcada por el rito de iniciación que suponía haber matado a un jabalí (Duris de Samos, F.Gr.Hist. 76, F 49 = Ateneo, I, 18 A) ${ }^{40}$.

En realidad a lo largo de toda la historia griega convivieron las posturas sentada y reclinada en la celebración de los banquetes, y desde Heródoto (I, 172) se señaló también que la distribución de los comensales tampoco tenía que estar al azar, como en el banquete helénico, sino por edad y jerarquía. Así fue también el banquete romano, que reproducía las jerarquías sociales a través de la distribución de los comensales ${ }^{41}$.

\footnotetext{
${ }^{38}$ Véase J. Rey CAStiÑEIRA, “A metalurxia...”, pág. 78.

${ }^{39}$ F. CoOper y S. Morris, "Dining in Round Buildings", en O. Murray (ed.), Sympotica. A Symposium on the Symposion, Oxford, Oxford University Press, 1990, págs. 67-85.

${ }^{40}$ Véase J. Bremmer, “Adolescents, Symposion and Pederasty”, en O. Murray (ed.), Sympotica..., págs. 135-148.

${ }^{41}$ J. D'Arms, “The Roman Convivium and Equality”, en O. Murray (ed.), Sympotica. A Symposium on the Symposion, Oxford, Oxford University Press, 1990, págs. 308-320.
} 
En las fuentes escritas nos encontramos además con informaciones relativas a diversas prácticas rituales, aunque como ya se ha señalado, su dimensión religiosa no está totalmente establecida, hecho que se añade a las propias características de las fuentes de este tipo (período al que se refieren, grupo étnico implicado, etc.). Así, por ejemplo, Estrabón (III, 3, 7) dice que los cántabros se casan como los griegos, lo que puede estar indicando quizás un aspecto del ritual, pero es imposible ir más allá ${ }^{42}$.

Asimismo, Estrabón, III, 3, 7 afirma que los montañeses del norte de Hispania precipitan a los condenados a muerte, lapidan a los parricidas más allá de las montañas y los cursos de agua. Este tipo de ejecuciones no eran ajenas a la tradición cultural de Estrabón ${ }^{43}$. En el caso de la precipitación en concreto, su carácter no es solo ritual a secas, sino de hecho religioso, en el sentido de que equivaldría a una ordalía, a entregar a la persona acusada a una divinidad para que dispusiese de su vida. Pero una vez más, la falta de detalle en la descripción nos impide ir más allá.

También podría añadirse la mención en Estrabón, III, 4, 16 acerca de los cantos y danzas que en las noches de plenilunio realizan los pueblos que limitan al norte con los celtíberos, venerando a un dios anónimo. Evidentemente, ante esta simple frase no es posible determinar de qué clase de rito se está hablando, ni siquiera a qué pueblos concretos está haciendo referencia Estrabón, así que no tiene sentido especular sobre ello.

\section{SANTUARIOS Y LUGARES DE CULTO}

Al hilo del apartado anterior, ya hemos mencionado algunos de los posibles lugares de culto o de celebración de actividades rituales en la cultura castreña. Así, quedan ya descritas tanto las saunas, si efectivamente se defiende la existencia de ritos iniciáticos ligados a clases de edad y/o a la actividad guerrera, como las propias casas o cabañas de gran tamaño quizás vinculadas a las celebraciones comunitarias que incluían la comensalidad.

En el interior de algunos de los asentamientos castreños se han identificado lugares que bien por su posición central y separada del resto del hábitat, o bien por la presencia de elementos que los relacionan con los llamados santuarios rupestres, que luego comentaremos, podrían estar dedicados a usos religiosos o rituales.

Así, en algunos de los grandes castros del sureste se aprecian recintos delimitados por un muro, situados en el centro del asentamiento y en su parte más

\footnotetext{
${ }^{42}$ Véase un análisis de las noticias de Estrabón sobre el sistema matrimonial de los pueblos del Norte en J. C. Bermejo BarRera, Sociedade e relixión ..., cap. II.

${ }^{43}$ Véase J. C. Bermejo Barrera, Sociedade e relixión..., pág. 36.
} 
elevada, donde no se aprecian huellas de uso cotidiano y sí quizás de un uso de otro tipo. En el recinto central de Monte Mozinho aparecen restos de ánforas y de vasijas del tipo terra sigilata hispánica, así como restos óseos de animales aparentemente quemados (que podrían estar relacionados con el sacrificio y/o la comensalidad de los que hablamos en el epígrafe anterior). En San Cibrán de Las también se aprecia un gran recinto amurallado sin huellas de actividades cotidianas o residenciales, en el que se han encontrado dos inscripciones, una de ellas ilegible, y la otra dedicada a Júpiter, divinidad que según Tranoy ${ }^{44}$ sería una de las utilizadas para llevar a cabo el sincretismo religioso ya en época romana, lo que también lleva a pensar en un recinto dedicado a fines religiosos o rituales, y de nuevo a una época relativamente tardía. En Sanfins, en este caso en el espacio creado por las dos vías de tránsito que organizan el castro, se levantó un edificio de grandes dimensiones, donde se localizaron dos aras anepígrafas y fragmentos de una estatua de guerrero. Todas estas menciones corresponden a grandes oppida de la fase final de la cultura castreña, pero en Chao Samartín (Asturias) se ha identificado un recinto, datado en el siglo VIII a.C. ${ }^{45}$, a cuya entrada se encontró una cista con un cráneo depositado. De todos modos, habría que insistir una vez más en la necesidad de no caer en la tentación de construir una cultura homogénea en el espacio y en el tiempo cuando las evidencias son tan escasas, puesto que la mera presencia de recintos aparentemente similares (aunque se sostenga que, puesto que no se perciben huellas de actividad cotidiana, su finalidad sería ritual), no nos dice nada de esa finalidad concreta, por lo que sería un abuso hablar de rituales semejantes en los castros de los inicios de la cultura castreña y en los grandes oppida de la fase final.

También dentro de algunos castros se han identificado lugares que por su especial configuración podrían estar relacionados con la celebración de los sacrificios a los que hemos aludido en el apartado anterior. Así, en el castro de Santomé y en el de Veiga, ambos en Ourense, se han identificado piletas, rebajes en la roca, y en el primer caso, con un posible recinto rectangular de mampostería rodeando la roca, como sucede también en el castro de Coto de Amoreira (Porto do Son, A Coruña). Asimismo, en el castro de Novás también se localizó una roca con cazoletas y rebajes, rodeada por un muro rectangular. En este caso, al parecer existe un nivel prerromano que sella las escaleras de acceso a la roca ${ }^{46}$.

\footnotetext{
$\overline{44}$ A. Tranoy, La Galice..., pág. 325.

45 Ángel Villa Valdés y Luis Cabo Pérez, "Depósito funerario y recinto fortificado de la Edad del Bronce en el castro de Chao Samartín: argumentos para su datación", Trabajos de Prehistoria, 60 (2) (2003), págs. 143-151.

${ }^{46}$ Antonio Rodríguez Colmenero, Prudencio Torres López y Manuel Menor Currás, "Excavaciones arqueológicas en el castro de Novás (Orense)", Noticiario Arqueológico Hispánico. Arqueología, 4 (1976), págs. 547-584.
} 
Junto con estas zonas dentro de los castros, parecen hallarse también estos lugares rituales especializados fuera de los recintos de habitación, los llamados habitualmente santuarios rupestres, aunque de nuevo los problemas de cronología son los más obvios. Ya desde los inicios de la investigación sobre la cultura castreña se describen este tipo de lugares, aunque su estudio ha sufrido vaivenes a lo largo de la historia de esa investigación ${ }^{47}$. El conjunto de los lugares citados varía un tanto según los autores ${ }^{48}$, pero se han identificado lugares de este tipo sobre todo en el noreste de Portugal y la zona sudoriental de Ourense. Se componen generalmente de escaleras talladas en la roca que llevan hacia una plataforma superior donde se han excavado cazoletas y piletas, así como posibles agujeros de poste en algunos casos. En Pía de Mougás (Oia) aparece una inscripción, así como en Mogueira (Resende, Lamego), lo que nos lleva a los problemas de cronología casi endémicos que mencionábamos anteriormente.

Está claro que estos santuarios se mantenían en uso en época ya romana, a juzgar no solo por las inscripciones, sino por la aparición de materiales romanos. El parecido formal con el santuario de Ulaca en Ávila, que se dataría en el período de los siglos III-I a.C. ${ }^{49}$, lleva a pensar que también los santuarios del Noroeste estarían en uso en época plenamente castreña. Otro punto a favor de esa presencia prerromana, según González Ruibal sería el hecho de que los que aparecen dentro de recintos castreños lo hacen en yacimientos que raramente son de nueva planta, de época romana ${ }^{50}$.

Un lugar especialmente interesante es el Facho de Donón, que condensa todos los problemas de la religión en la cultura indígena (o culturas) del Noroeste que hemos estado comentando, aunque su cronología nos lleva muy lejos de esta cultura y por lo tanto apenas haremos unas indicaciones ${ }^{51}$. Se trata de un san-

\footnotetext{
47 A. GonzÁlez Ruibal, "Galaicos...”, págs. 563-564.

48 Por ejemplo, A. C. DA Silva, A cultura castreja ..., pág. 300, que se centra en el tardío Panóias; véanse las obras de síntesis más recientes de A. GonzÁlez Ruibal, "Galaicos...”, págs. 562 y ss. y J. Rodríguez Corral, A Galicia castrexa ..., págs. 170 ss.

49 Jesús R. Álvarez Sanchís, Los Vettones, Madrid, Real Academia de la Historia, 2003, pág. 148.

50 A. GonzÁlez Ruibal, “Galaicos...”, pág. 565.

${ }^{51}$ Sobre el yacimiento de O Facho puede verse Francisco FAriña Busto y José SuÁrez Otero, "El santuario galaico-romano de O Facho (Hío, Pontevedra)", Boletín Auriense, XXXII (2002), págs. 25-52. Thomas G. Schattner, José SuÁrez Otero y Michael Koch, "Monte do Facho, Donón (O Hío / Prov. Pontevedra) 2003. Informe sobre las excavaciones en el santuario de Berobreo", Archivo Español de Arqueología, 77 (2004), págs. 23-71; Thomas G. Schattner, José SuÁrez Otero y Michael $\mathrm{KoCH}$, "Monte do Facho 2003. Bericht über die Ausgrabungen im Heiligtum des Berobreus", Madrider Mitteilungen, 46 (2005), pág. 135-183; Thomas G. Schattner, José SuÁrez Otero y Michael Koch, "Monte do Facho 2004. Bericht über die Ausgrabungen im Heiligtum des Berobreus", Madrider Mitteilungen, 47 (2006), págs. 169-192; Thomas G. Schattner, José SuÁrez Otero y Michael Koch, "Weihaltäre im Heilingtum des deus lar Berobreus aus dem Monte do Facho (O Hío, Galicien)", en Alexandra W. Bush y Alfred Schäfer (eds.), Römische Weihealtäre im Kontext, Köln, Likias, 2014,
} 
tuario con una importantísima colección de aras votivas dedicadas al Deus Lar Berobreus. Este santuario se desarrollaría a partir de la segunda mitad del siglo III d. C. (y se extendería hasta comienzos del siglo V d.C.), dos siglos después de ser abandonado el castro adyacente, pero el nombre de la divinidad, Berobreo según las lecturas más aceptadas ${ }^{52}$, es indígena. Su calificación como Deus Lar correspondería quizás al mecanismo de interpretatio romana descrito por A. Tranoy $^{53}$; teniendo en cuenta que en parte de las aras aparece la fórmula pro salute o salute, seguramente nos encontramos ante un dios medicinal. Su culto podría ser incluido en el renacimiento de los cultos célticos e indígenas de dioses medicinales y héroes que se produce en la Galia y en el occidente romano ${ }^{54}$.

\section{DiOSES Y PANTEONES}

Dice Estrabón (III, 4, 16) que según algunos autores, los galaicos son ateos. Dejando de lado lo que quiera decir exactamente con esta palabra el autor griego ${ }^{55}$, es evidente que los aproximadamente doscientos teónimos que se conservan en la epigrafía de la zona dejarían claro que no hay tal ausencia de divinidades. Como ya se ha señalado, los testimonios sobre divinidades de la zona castreña provienen de la epigrafía latina, de época bastante tardía por lo tanto, aunque referidas en muchos casos a divinidades de indudable carácter indígena. Ya se ha indicado también que en la mayoría de los casos solo disponemos del nombre de la deidad, no siempre totalmente establecido: las lecturas varían, no está clara incluso su adscripción a un grupo lingüístico determinado, y se ignora a veces incluso si se trata de una divinidad masculina o femenina ${ }^{56}$. Puesto que solo se conocen los nombres, lingüistas e historiadores de la religión han intentado desvelar el carácter de los dioses prerromanos y los rasgos principales de sus cultos a partir de la etimología ${ }^{57}$. Estos esfuerzos por establecer el carácter de las divinidades a través exclusivamente de sus nombres resultan ser un empeño bastante estéril: el hecho de conocer un teónimo o de conseguir establecer su etimología no supone

\footnotetext{
págs. 249-268; Pilar Barciela Garrido et al., Para o deus Berobreo. Aras do santuario de Donón no Museo Municipal de Vigo, Vigo, Museo Municipal Quiñones de León, 2005.

52 No obstante, A. Tranoy, La Galice..., pág. 293, rechaza la lectura Deo Lar Berobreo y propone Laribero Breo; véase también Juan Carlos Olivares Pedreño, Los dioses de la Hispania céltica, Madrid, Real Academia de la Historia-Universidad de Alicante, 2002, págs. 68-69 que se decanta igualmente por Laribero.

53 A. Tranoy, La Galice..., pág. 323.

${ }^{54}$ Véase sobre este fenómeno Aline Rousselle, Croire et guérir. La foi en Gaule dans l'Antiquité tardive, París, Fayard, 1990.

55 Véase J. C. Bermejo Barrera, Sociedade e relixión ..., págs. 39 y ss.

56 Véase un listado de nombres de las divinidades indígenas recogidas en los conventos del Noroeste en A. Tranoy, La Galice..., págs. 266, 287, 295.

57 Véase un intento reciente en B. M. PrósPer, Lengua y religiones...
} 
llegar a dilucidar el campo de acción de una divinidad, puesto que, entre otras cosas, los nombres propios no tienen significado. Puesto que no tenemos narraciones en las que intervengan esas divinidades ni conocemos los rituales dirigidos a ellas, aparte de las propias dedicatorias, establecer, en el mejor de los casos, el significado etimológico de su nombre es solamente un indicio más para poder aproximarnos a un panteón abundante y complejo ${ }^{58}$.

Toda esta abundancia de divinidades ha sido objeto de intentos diversos de clasificación y de explicación: por su ámbito de actividad (de la guerra, de los caminos), por su asociación o incluso identificación con elementos naturales (de las aguas, de los peñascos, bosques o incluso del paisaje), por el territorio sobre el que ejercen su acción (generales, locales), por su carácter "étnico" (indígenas, latinos con epítetos indígenas) ${ }^{59}$... Evidentemente, es imposible abordar un estudio detallado ni completo en el marco de este trabajo ${ }^{60}$.

A pesar de las aproximaciones diferenciadas, parece existir un cierto acuerdo a la hora de considerar que Bandua, Coso, Nabia y Reve (con sus distintas grafías) son las divinidades de carácter indígena con más menciones y una más amplia distribución, que abarca no solo el territorio de lo que sería la Gallaecia romana, sino también la Lusitania ${ }^{61}$.

Bandua tiene menciones epigráficas en los dos territorios mencionados. Los intentos de comprensión de esta divinidad van desde su vinculación con la segunda función indoeuropea, relacionada con la guerra por lo tanto, aunque con vinculaciones con la magia relacionada con la primera función ${ }^{62}$, hasta su carácter de deidad protectora de la comunidad, de un tipo similar a genius o lar, puesto que su propio nombre se traduciría así6 ${ }^{6}$. No obstante, Prósper propone que su nombre

\footnotetext{
${ }^{58}$ Sobre las limitaciones de la etimología para la historia de las religiones, véase J. C. BERMEJO Barrera, Sociedade e relixión..., págs. 109 y ss.

${ }^{59}$ Véase Juan Carlos Olivares PedreÑo, "Teónimos indígenas masculinos del ámbito galaico-lusitano: un intento de síntesis", Revista de Guimarâes, volume especial, I (1999), págs. 277-296, donde se recogen las distintas aproximaciones clasificatorias.

${ }^{60}$ Pueden verse trabajos de conjunto relativamente recientes en Blanca García Fernández-AlbaLAT, Guerra y religión en la Gallaecia y la Lusitania antiguas, Sada, Ediciós do Castro, 1990; J. C. Olivares Pedreño, Los dioses...; B. M. Prósper, Lengua y religiones.... En todos ellos se recogen los trabajos previos.

${ }^{61}$ Véanse los mapas de distribución de los epígrafes en B. García Fernández-Albalat, Guerra y religión ...; J. C. Olivares Pedreño, Los dioses...; B. M. Prósper, Lengua y religiones....

${ }^{62}$ Ésta es la opción defendida por ejemplo por B. García Fernández-Albalat, Guerra y religión ... y Rosa Brañas Abad, Deuses, heroes e lugares sagrados na cultura castrexa, Santiago, Sotelo Blanco, 2000; "Entre mitos, ritos y santuarios. Los dioses galaico-lusitanos", en Francisco Javier González García (coord.), Los pueblos de la Galicia céltica, Madrid, Akal, 2007, págs. 377-443.

${ }^{63}$ Es la opción por la que se decantan autores como J. C. Olivares Pedreño, Los dioses ..., págs. 151 ss., donde se recogen aquellos autores anteriores que ya apuntaban esta solución.
} 
procede de "vado" o "paso", y la divinidad no sería más que la personificación del acceso al poblado ${ }^{64}$. Lo cierto es que considerar a una divinidad protectora de la comunidad que le da culto no es en absoluto una explicación sobre su sentido.

Coso, por otra parte, había sido interpretado como una divinidad de carácter guerrero, relacionada con las asambleas de tipo céltico a partir de uno de sus epítetos, Oenaeco ${ }^{65}$. Su relación con el Marte romano y con el Ares que menciona Estrabón (véase supra) ya había sido estudiada hace años por Bermejo Barrera ${ }^{66}$. Olivares Pedreño señala también el hecho de que las inscripciones al llamado "Marte indígena" no coinciden con las de Coso (o Bandua), lo que podría estar indicando que su culto sustituye al de estas divinidades más antiguas ${ }^{67}$. Prósper sin embargo relaciona a esta divinidad también con las reuniones, y además con las "confluencias", incluyendo las de los ríos ${ }^{68}$.

Olivares Pedreño destaca la complementariedad que existe a su parecer entre Bandua y Coso, cuyos territorios de culto no se solaparían más que en dos zonas: la ría de Arousa y Aveiro ${ }^{69}$. Esta distribución de los epígrafes de ambas divinidades le lleva a pensar que sus funciones serían parecidas, así que Coso estaría también relacionado con la protección de la comunidad.

Nabia (o Navia) aparece en inscripciones en los conventos lucense y bracarense y también en la Lusitania, en la zona de Cáceres ${ }^{70}$. Su aparición en la inscripción de Penafiel calificada como Ninfa ha apoyado su interpretación como una divinidad asociada a las fuentes y las aguas en general, al menos en alguna de sus manifestaciones ${ }^{71}$. García Fernández-Albalat, sin embargo la considera una divinidad relacionada con la guerra a través de su vinculación con los ríos, que, dentro de la hipótesis céltica general de esta autora, serían entradas en el más allá ${ }^{72}$.

La etimología que ofrece Prósper de nuevo alude a una característica de la naturaleza o del paisaje, que como estamos viendo es lo dominante en las interpretaciones de esta autora. Así, Nabia se relaciona con la actual nava, y sería la forma general utilizada para "valle" en la lengua o lenguas de la zona ${ }^{73}$.

\footnotetext{
${ }^{64}$ B. M. Prósper, Lengua y religiones..., págs. 272, 274.

${ }^{65}$ B. García Fernández-Albalat, Guerra y religión..., págs. 26 y ss.

${ }^{66}$ J. C. Bermejo barrera, Mitología y mitos ..., págs. 87-106; véase también Sociedade e relixión..., cap. IX.

67 J. C. Olivares Pedreño, Los dioses..., págs. 159 y ss.

${ }^{68}$ B. M. Prósper, Lengua y religiones..., págs. 225 y ss.

${ }^{69}$ J. C. Olivares Pedreño, Los dioses..., pág. 158, y esp. mapa núm. 14, pág. 159.

${ }^{70}$ Véase J. C. Olivares Pedreño, Los dioses..., pág. 233; véanse los mapas de distribución de los epígrafes en B. García Fernández-Albalat, Guerra y religión ... mapa 3; B. M. Prósper, Lengua y religiones..., mapa 11, pág. 510.

${ }^{71}$ A. Tranoy, La Galice..., pág. 282.

${ }^{72}$ B. García Fernández-Albalat, Guerra y religión ..., cap. VI.

${ }^{73}$ B. M. PrósPer, Lengua y religiones..., pág. 194.
} 
De nuevo habría que indicar que la etimología no nos dice nada sobre el carácter de la divinidad. Olivares Pedreño recupera en parte algo que ya había señalado Tranoy sobre el carácter de gran divinidad suprarregional de Nabia, atestiguado en la amplia distribución territorial de sus epígrafes, y así señala el hecho de que sea la única divinidad femenina supralocal en el territorio al norte del Duero ${ }^{74}$, lo que le lleva a plantear la hipótesis de que Nabia sea una divinidad polifuncional similar a otras diosas de las mitologías indoeuropeas como Juno, Sarasvati o las Morrigan irlandesas ${ }^{75}$.

Para finalizar este breve repaso de las divinidades indígenas más representadas en la epigrafía, acerca de Reve, que ha sido una deidad considerada alternativamente masculina o femenina ${ }^{76}$, se repiten los argumentos generales que hemos venido recogiendo para las demás divinidades. Así, su relación con los ríos o cursos de agua está presente en Prósper, que de hecho sostiene que Reve significa exactamente "río"; García Fernández-Álbalat, además de considerarla una divinidad femenina, la pone en relación con la idea de "llanura" mítica, relacionada con el otro mundo y con la conducción de los guerreros muertos en batalla al más allá; Olivares Predreño por su parte sostiene que Reve sería una divinidad semejante a Júpiter, a partir de su vinculación con las montañas, una divinidad soberana por lo tanto, pero que sobrepasaría el ámbito más local de Bandua o Coso y se convertiría en garante de las relaciones intracomunitarias ${ }^{77}$.

Para finalizar este repaso a la religión de los pueblos del Noroeste (y siendo conscientes de las oscilaciones en la denominación y en el ámbito territorial y cronológico que estamos tratando), es interesante mencionar aunque sea de pasada la cuestión de la adaptación a la religión romana, que parece haberse producido a través de la interpretación de las divinidades indígenas en clave romana, o de las divinidades romanas en clave indígena, representada sobre todo en los cultos a Júpiter, Marte, las Ninfas o los Lares con epítetos indígenas ${ }^{78}$. Así, Penas Truque sostiene que, en el caso concreto de la vinculación de las divinidades con las montañas, se desarrollan en paralelo dos tipos de culto: por un lado el culto a un dios de la segunda función asociado a Marte, y por otro, el culto a Júpiter, unido al culto al emperador, como medio de cohesión social entre indígenas y romanos ${ }^{79}$; en el

\footnotetext{
74 J. C. Olivares Pedreño, Los dioses..., págs. 237.

${ }^{75}$ Cuestión que ya había sido planteada, en este último caso, por B. García Fernández-Albalat, Guerra y religión..., pág. 308.

76 Véase J. C. Olivares Pedreño, Los dioses ..., pág. 169.

77 Respectivamente en B. M. Prósper, Lengua y religiones ..., pág. 142, B. García Fernández-ALBalat, Guerra y religión..., pág. 322 y J. C. Olivares Pedreño, Los dioses ..., págs. 171 y 185.

78 Véase en A. Tranoy, La Galice..., págs. 300-301 un cuadro con los teónimos.

$79 \mathrm{M}^{\mathrm{a}}$ de los Ángeles Penas Truque, "Los dioses de la montaña", en J.C. Bermejo Barrera, Mitología y mitos..., págs. 117-140.
} 
caso concreto de los Lares Viales, en este caso ya con la denominación latina, los numerosos epígrafes a estas divinidades que se conservan en el Noroeste estarían recubriendo a una divinidad de carácter indudablemente indígena ${ }^{80}$.

Los historiadores y los arqueólogos caemos a veces en la tentación de confundir la totalidad del pasado con la visión global del mismo, que es la meta que intentamos alcanzar en nuestros estudios. Por supuesto que el pasado, como cualquier otro objeto de estudio, jamás podrá ser captado en su totalidad. Pero en el caso de los estudios arqueológicos e históricos debemos tener en cuenta que un elemento esencial para permitir la reconstrucción de visiones globales es la existencia de diferentes tipos de fuentes en la mayor cantidad posible. Ya hemos visto cómo las visiones globales de la religión castreña están condicionadas por ellas y cómo además la inexistencia de fuentes documentales o literarias "indígenas" en el sentido antropológico del término, es decir, de textos en los que podamos ver de modo directo cómo se expresan las personas que compartían las creencias religiosas y mitológicas y practicaban los ritos de este mundo concreto, dificultan esta reconstrucción.

Lo que hemos ofrecido es una síntesis provisional, como cualquier síntesis histórica, partiendo de la documentación existente; hemos intentando presentar las conclusiones a las que los arqueólogos e historiadores de diferentes orientaciones metodológicas han llegado en sus estudios, intentado evitar la tentación de la totalidad y la tentación del sistema, que consiste en creer que solo una única teoría histórico-religiosa o arqueológica puede dar cuenta de la realidad histórica del pasado. Y lo hemos hecho así porque en esos casos el apriorismo de la teoría y la fidelidad a una escuela son las que proporcionan la sensación de seguridad e infalibilidad de la interpretación que se propone. Creemos que la historia y la arqueología se benefician mucho más del diálogo entre interpretaciones que de la construcción de grandes sistemas, y por hemos intentado llevar a cabo este estado de la cuestión como punto de partida para el desarrollo de las nuevas investigaciones del futuro.

\section{BiBLIOGRAFÍA}

Álvarez Sanchís, Jesús R., Los Vettones, Madrid, Real Academia de la Historia, 2003.

Armada Pita, Xosé Lois y García Vuelta, Óscar, "Bronces con motivos de sacrificio del área noroccidental de la península Ibérica”, Archivo Español de Arqueología, 76 (2003), págs. 47-75.

\footnotetext{
${ }_{80}$ Véase A. Tranoy, La Galice..., págs. 323 ss.; el estudio más amplio sobre los Lares Viales (publicado originariamente en 1978) puede verse en J.C. BERMEJo BARRERA, Sociedade e relixión...., cap. XI.
} 
Balboa Salgado, Antonio, Gallaecia nas fontes clásicas, Santiago de Compostela, Servicio de Publicacións da Universidade de Santiago de Compostela, 1996.

Barciela Garrido, Pilar et al., Para o deus Berobreo. Aras do santuario de Donón no Museo Municipal de Vigo, Vigo, Museo Municipal Quiñones de León, 2005.

Bermejo Barrera, José Carlos, Mitología y mitos de la Hispania prerromana II, Madrid, Akal, 1986.

Bermejo Barrera, José Carlos, Sociedade e relixión na Galicia antiga, Santiago de Compostela, Lóstrego, 2008.

Blázquez Martínez, José María, Religiones Primitivas de Hispania. I. Fuentes Literarias y epigráficas, Madrid, CSIC, 1962.

Blázquez Martínez, José María, Diccionario de las religiones Primitivas de Hispania, Madrid, Istmo, 1978.

Blázquez Martínez, José María, Imagen y Mito, Madrid, Ediciones Cristiandad, 1980.

Blázquez Martínez, José María, Primitivas Religiones Ibéricas. II. Religiones Prerromanas, Madrid, Ediciones Cristiandad, 1983.

Blázquez Martínez, José María, Religiones de la Hispania Antigua, Madrid, Cátedra, 1991.

Brañas Abad, Rosa, Deuses, heroes e lugares sagrados na cultura castrexa, Santiago, Sotelo Blanco, 2000.

Brañas Abad, Rosa, "Entre mitos, ritos y santuarios. Los dioses galaico-lusitanos", en Francisco Javier González García (coord.), Los pueblos de la Galicia céltica, Madrid, Akal, 2007, págs. 377-443.

Bremmer, J., "Adolescents, Symposion and Pederasty", en O. Murray (ed.), Sympotica. A Symposium on the Symposion, Oxford, Oxford University Press, 1990, págs. 135-148.

Caamaño Gesto, José Manuel, A cultura castrexa. Vol. 1. Ocupación do territorio e cultura material, A Coruña, Arrecife Edicións Galegas, 2007.

Castro Vigo, Eva, "Un nuevo ejemplo de los llamados bronces votivos sacrificiales”, Gallaecia, 28 (2009), págs. 131-138.

Cooper, F. y Morris, S., "Dining in Round Buildings", en O. Murray (ed.), Sympotica. A Symposium on the Symposion, Oxford, Oxford University Press, 1990, págs. 67-85.

D'Arms, J., "The Roman Convivium and Equality”, O. Murray (ed.), Sympotica. A Symposium on the Symposion, Oxford, Oxford University Press, 1990, págs. 308-320.

Dueck, Daniela, Strabo of Amasia. A Greek Man of Letters in Augustan Rome, Londres, Routledge, 2000.

Fariña Busto, Francisco y Suárez Otero, José, "El santuario galaico-romano de O Facho (Hío, Pontevedra)", Boletín Auriense, XXXII (2002), págs. 25-52.

García Fernández-Albalat, Blanca, Guerra y religión en la Gallaecia y la Lusitania antiguas, Sada, Ediciós do Castro, 1990.

García Quintela, Marco V. y Santos-Estévez, Manuel, "Iron Age saunas of Northern Portugal: state of the art and research perspectives", Oxford Journal Of Archaeology, 34 (1) (2015), págs. 67-95.

González Ruibal, Alfredo, “Galaicos. Poder y comunidad en el Noroeste de la Península Ibérica (1200 a.C.-50 d.C.)”, Brigantium, vol. 18-19 (2006-2007). 
Llinares García, Mar, "El jinete y sus caballos: a propósito del relieve castreño de Formigueiro (Amoeiro, Ourense)", Madrider Mitteilungen, 49 (2008), págs. 229-237.

Llinares García, Mar, Los lenguajes del silencio. Arqueologías de la religión, Madrid, Akal, 2012.

Olivares Pedreño, Juan Carlos, "Teónimos indígenas masculinos del ámbito galaico-lusitano: un intento de síntesis", Revista de Guimarâes, volume especial, I (1999), págs. 277-296.

Olivares Pedreño, Juan Carlos, Los dioses de la Hispania céltica, Madrid, Real Academia de la Historia-Universidad de Alicante, 2002.

Pena Graña, Andrés, “Cerimonias celtas de entronización real na Galicia”, Anuario Brigantino, 27 (2004), págs. 117-160.

Penas Truque, $\mathrm{M}^{\mathrm{a}}$ de los Ángeles, "Los dioses de la montaña", en J.C. Bermejo Barrera, Mitología y mitos de la Hispania prerromana II, Madrid, Akal, 1986, págs. 117-140.

Penedo Romero, Rafael, "Informe sobre los restos óseos del yacimiento castreño de Punta dos Prados (Ortigueira, A Coruña): campañas de 1987 y 1988”, Brigantium, 9 (1995-1996), págs. 61-74.

Prósper, Blanca María, Lengua y religiones prerromanas del occidente de la Península Ibérica, Salamanca, Ediciones Universidad de Salamanca, 2002.

Quesada Sanz, Fernando, “¿Espejos de piedra? Las imágenes de armas en las estatuas de los guerreros llamados galaicos”, Madrider Mitteilungen, 44 (2003), págs. 87-112.

Quiroga, Francisco Manuel Veleda Reimâo, War and Castros. New approaches to the northwestern Portuguese Iron Age, Oxford, Archaeopress, 2003 (BAR International Series 1198).

Rey Castiñeira, Josefa, "Referencias de tempo na cultura material dos castros galegos", en J.M. Hidalgo Cuñarro (coord.), A cultura castrexa a debate (Actas do Curso de Verán da Universidade de Vigo, Tui, 17-19 de xullo de 1995), Tui, Instituto de Estudios Tudenses, 1996, págs. 157-206.

Rey Castiñeira, Josefa, "A metalurxia castrexa" en J.M. Hidalgo Cuñarro (coord.), Arte e cultura de Galicia e norte de Portugal. Arqueoloxía, vol. 2, Vigo, Nova Galicia Edicións, 2005, págs. 57-83.

Rodríguez Colmenero, Antonio, Torres López, Prudencio y Menor Currás, Manuel, "Excavaciones arqueológicas en el castro de Novás (Orense)", Noticiario Arqueológico Hispánico. Arqueología, 4 (1976), págs. 547-584.

Rodríguez Corral, Javier, A Galicia castrexa, Santiago, Lóstrego, 2009.

Romero Masiá, Ana y Pose Mesura, Xosé Manuel, Galicia nos textos clásicos, A Coruña, Museo Arqueolóxico Provincial, 1988.

Rousselle, Aline, Croire et guérir. La foi en Gaule dans l'Antiquité tardive, París, Fayard, 1990.

Ruiz Zapatero, Gonzalo (coord.), "Un círculo de lectores: Miradas sobre los celtas del NO. de la Península Ibérica”, Complutum, 16 (2005), págs. 151-208.

Schattner, Thomas G., Suárez Otero, José y Koch, Michael, "Monte do Facho, Donón (O Hío / Prov. Pontevedra) 2003. Informe sobre las excavaciones en el santuario de Berobreo", Archivo Español de Arqueología, 77 (2004), págs. 23-71.

Schattner, Thomas G., Suárez Otero, José y Koch, Michael, "Monte do Facho 2003. Bericht über die Ausgrabungen im Heiligtum des Berobreus", Madrider Mitteilungen, 46 (2005), págs. 135-183. 
Schattner, Thomas G., Suárez Otero, José y Koch, Michael, "Monte do Facho 2004. Bericht über die Ausgrabungen im Heiligtum des Berobreus", Madrider Mitteilungen, 47 (2006), págs. 169-192.

Schattner, Thomas G., Suárez Otero, José y Koch, Michael, "Weihaltäre im Heilingtum des deus lar Berobreus aus dem Monte do facho (O Hío, Galicien)", en Alexandra W. Bush y Alfred Schäfer (eds.), Römische Weihealtäre im Kontext, Köln, Likias, 2014, págs. 249-268.

Schulten, Adolf y Bosch Gimpera, Pedro (eds.), Fontes Hispaniae Antiquae, Barcelona, Bosch, 1922-1959.

Silva, Armando Coelho Da, A cultura castreja no Noroeste de Portugal, Câmara Municipal de Paços de Ferreira-Museu Arqueológico da Citânia de Sanfins, 1986.

Tranoy, Alain, La Galice romaine. Recherches sur le nord-ouest de la péninsula ibérique dans l'Antiquité, París, Diffusion de Boccard, 1981.

Villa Valdés, Ángel, "Santuarios “urbanos" en la protohistoria cantábrica: algunas consideraciones sobre el significado y función de las saunas castreñas", Boletín del Real Instituo de Estudios Asturianos, LXV, 177 (enero-junio. 2011), págs. 9-46

Villa Valdés, Ángel y Cabo Pérez, Luis, "Depósito funerario y recinto fortificado de la Edad del Bronce en el castro de Chao Samartín: argumentos para su datación", Trabajos de Prehistoria, 60 (2) (2003), págs. 143-151. 